\title{
FACTORS AFFECTING CITIZENS' INTENTION TO CONTINUE USING THE REWARDING SOLID-WASTE COLLECTION MOBILE APPS IN TEHRAN, IRAN
}

\author{
F. Behnamifard ${ }^{1 *}$, H. Ahmady ${ }^{2}$, H. Shokri ${ }^{3}$ \\ ${ }^{1}$ School of Architecture and Environmental Design, Iran University of Science and Technology, Tehran, Iran, \\ f_behnamifard@arch.iust.ac.ir \\ ${ }^{2}$ Dept. of Urban Planning, Islamic Azad University, Ahvaz Branch, Ahvaz, Iran, h.ahmady@iauahvaz.ac.ir \\ ${ }^{3}$ Dept. of Urban Design, Islamic Azad University, Ahvaz Branch, Ahvaz, Iran, hoda.urbanism@gmail.com
}

KEY WORDS: Smart waste management, Waste collection mobile apps, Waste segregation, Smart city, Smart citizenship, Citizen engagement

\begin{abstract}
:
Despite technological advances in waste recycling and management, many developing countries, including Iran, are still in the early stages of this process: the segregation and collection of recyclable waste. In this regard, to increase citizens' coope ration in household waste segregation, a rewarding solid-waste collection system has been established in the metropolises of Iran. In such circumstances, it is evident that maintaining the continued use of citizens without compromising their satisfaction has become an essential concern in the development of a sustainable waste collection and recycling system in Iran. For this reason, the present study tries to investigate the factors affecting citizens' continuous intention to use the rewarding solid-waste collection (RSWC) mobile apps in Tehran (the capital of Iran). In this regard, first, the conceptual model of the re search is obtained by combining the widely used ECM model with D\&M's IS success model. Then, the questionnaire designed based on previous studies was provided to the citizens, and out of a total of 373 completed questionnaires, by removing the incomplete ones, 302 questionnaires were finally analysed. A partial least squares (PLS) analysis based SEM using SmartPLS was performed to assess the model and verify hypotheses. Results show that various variables significantly influence users' continuous intention to use RSWC mobile apps. Meanwhile, RSWC mobile apps should improve their platform quality and rewarding system, strengthen their content quantity, and ensure the consistency between their service and citizens' satisfaction.
\end{abstract}

\section{INTRODUCTION}

Ever since the advent of technology and at various stages of its development and influence in urban life, there has always been a concern about how much it is to be accepted and used by the people (Behnamifard et al., 2020). The emergence of the Smart City approach has also contributed to this concern. One of its main goals is to combine innovative virtual world technologies with the capabilities of the physical world in the complex urban environment to provide integrated access to urban services for citizens and improve their quality of life (Laartz, Lulf, 2014; Šiuryte, 2015). Thus, moving towards urban smartness depends on the existence of empowered citizens who can use the technological context of the city and its tools and be diligent in its development and promotion (Šiuryte, 2015).

For this reason, in recent years, urban experts and innovators have made significant efforts to use new ICT tools to facilitate citizens' use of urban services and provide the opportunity for their interaction and involvement in various urban affairs (Stratigea et al., 2015). Regarding the importance of this issue, researchers have also tried to explore citizens' views to identify the factors and obstacles affecting the adoption of egovernment (e.g., Colesca, Dobrica, 2008; Mensah et al., 2017; Veeramootoo et al., 2018; Wang, Liao, 2008), m-government (e.g., Abu-Shanab, Haidar, 2015; Almarashdeh, Alsmadi, 2017; Ishengoma et al., 2018), or various urban ICT-based services and their use in this field (e.g., Böhm et al., 2015;
Praharaj et al., 2017; Susanto et al., 2017; Walravens, 2014; Wilson et al., 2019; Winkler et al., 2012; Yeh, 2017). One of the most critical urban issues that have received less attention in such studies is waste management. This can be attributed to the significant differences in countries' experiences in providing ICT-based services in this field.

Waste management includes various stages, from waste segregation and collection to waste recovery and recycling. So far, depending on the different technological advances in different parts of the world, various solutions have been provided to improve these stages. These strategies are less diverse in developing countries. On the one hand, despite the more challenging waste management in these countries, the social and systematic conditions governing the waste collection process are in poor condition and have stopped recycling the waste in the early stages (Medina, 2008). On the other hand, the digital inequality between the world's countries has caused many developing countries to lag behind the developed countries in technology infrastructure (Praharaj et al., 2017). For this reason, well-thought-out ICT-based solutions in these countries can often be limited to waste collection.

Waste collection as the first step of the waste management process is an important and complex step that, in addition to the cooperation of citizens, requires comprehensive logistics management and high costs. This stage occurs informally (mostly by poor people) in many developing and low-income

\footnotetext{
${ }^{*}$ Corresponding author
} 
countries (Coelho et al., 2019; Medina, 2008). One solution devised in these countries is to digitize household waste collection through mobile applications that act as a bridge between households, collectors, and recycling companies. For example, an application designed in Ghana connects (2020), with the municipality's permission, first designed a mobile app to collect household waste at the time specified by the user at his/her doorstep, then descriptively and based on citizens' views, evaluated different qualities affecting the app usage.

Iran's experience in this field is similar to the experiences of Ghana and the Philippines and includes the creation of the rewarding solid-waste collection system from late 2019. In this system, by granting licenses to private companies willing to cooperate, the municipalities have made it possible to develop one or more mobile applications in each city. The process of these rewarding solid-waste collection (RSWC) mobile apps is invariant. After installing the app and registration, citizens, households with the collection agent in real-time and, while recording the cooperation history and paying the citizens' reward, also shows them the work schedule of the collectors the next day (Mwikali, 2020). In the Philippines, Ablaza-Cruz

when needed, can determine the type and volume of their waste (or even capture its image if desired) and schedule the delivery time and day for the collection agent. After submission of the user's request, for further coordination, the company will call the user's registered phone number in the app, and the collection agent will be sent to the user's residence at the desired date and time. As the collection agent arrived, he first measures the weight of each type of solid waste in the consignment and records it in the user's profile. Thus, according to the records, the user's monetary reward will be calculated and deposited in his/her digital wallet. This reward can be directly withdrawn or used to purchase or enjoy various discounts in the app. Figure 1 shows the submission steps of the user request in one of the RSWC mobile apps in Tehran. (a)
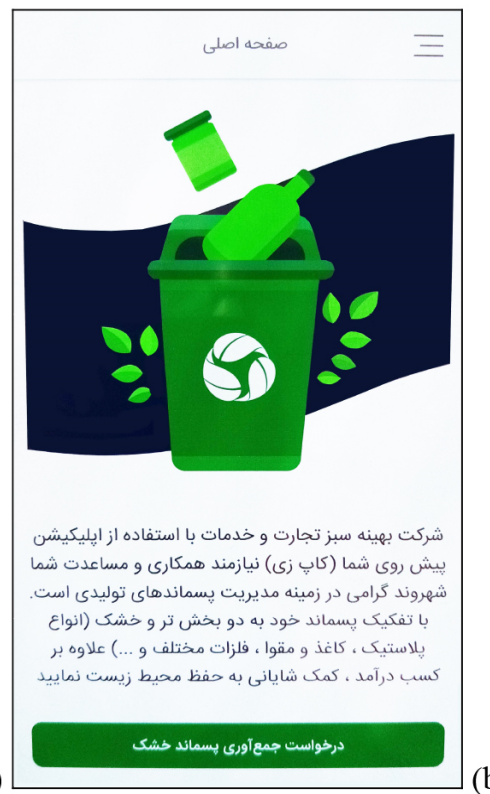

(d)

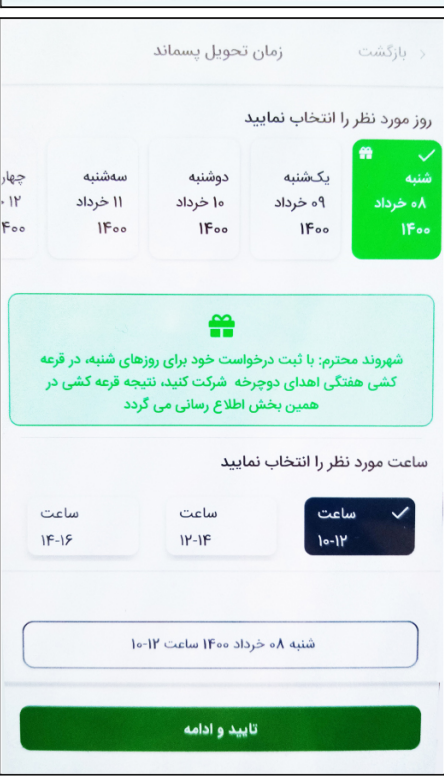

(b)
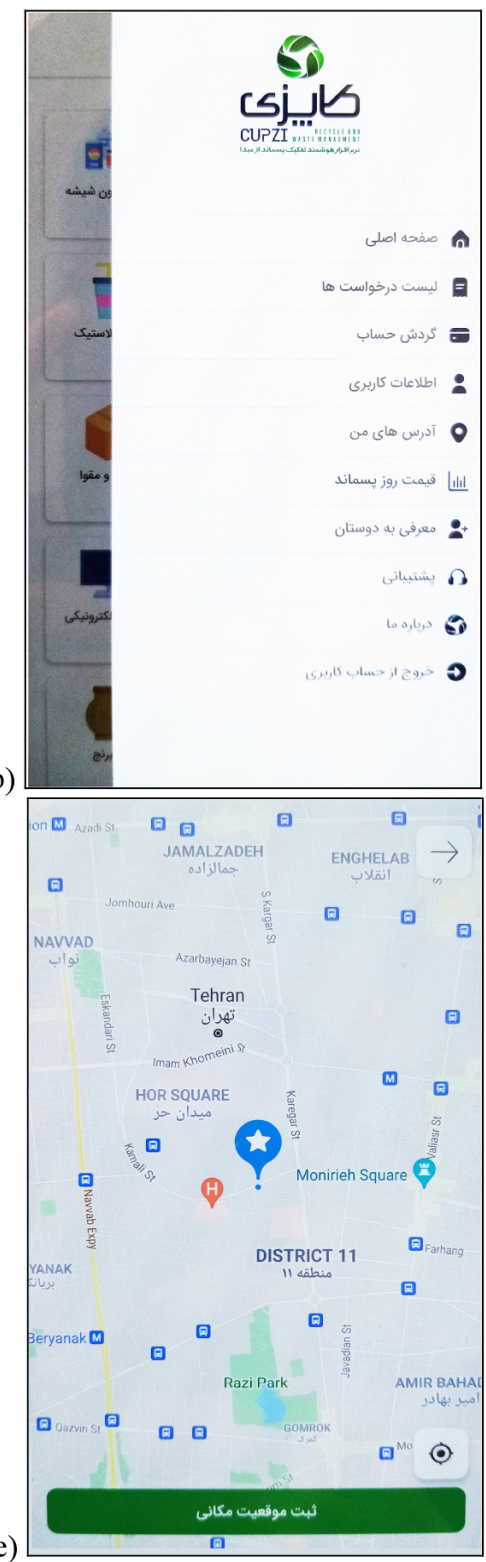

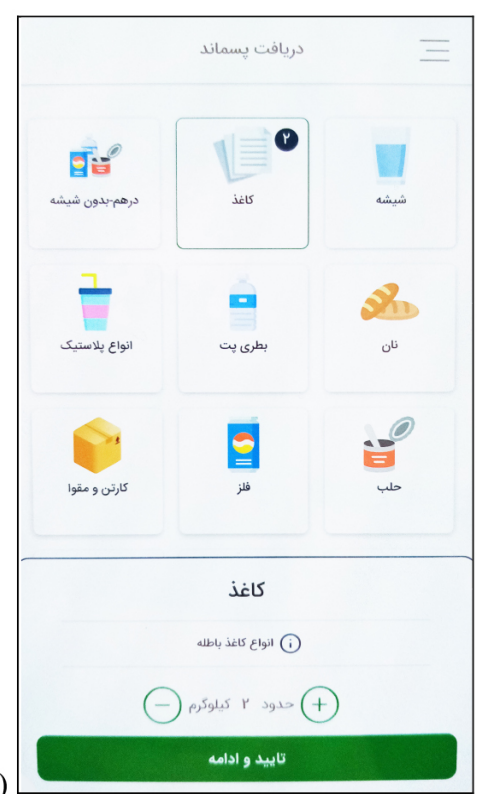

(c)

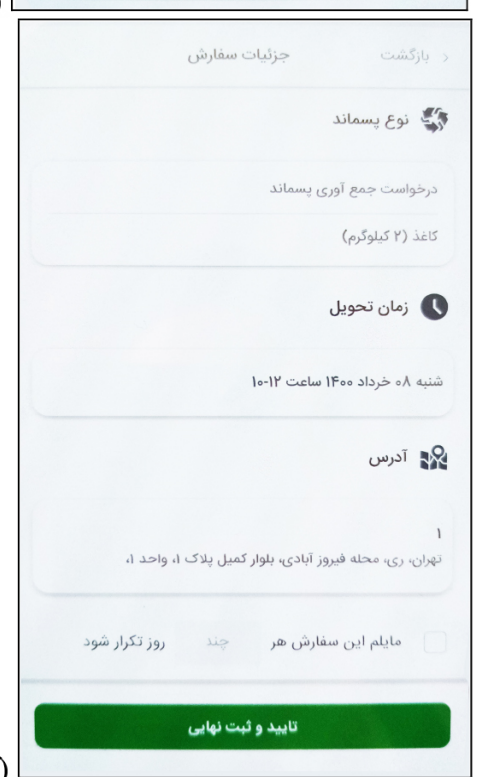

Figure. 1. An example of the demand registration process in RSWC mobile apps in Tehran (CUPZI app), respectively: (a) Home screen, (b) account functionalities, (c) solid-waste type, and weight determination screen, (d) collection day and time setting screen, (e) address registration, and (f) final approval screen (Source: https://cupzi.app/) 
In this regard, this study aims to identify the factors affecting citizens' satisfaction and continuous intention to use these applications, focusing on the experience of Tehran residents in using RSWC mobile apps. First, the D\&M IS success model is used to examine the impact of RSWC mobile apps' quality on user satisfaction. Then, by combining RSWC mobile apps' quality with the Expectation-confirmation model, the factors affecting users' willingness for continuous use of the RSWC mobile apps are analysed. The findings of this study are expected to fill the existing research gap in citizens' perceptions of RSWC mobile apps and provide theoretical support for sustainable community management in participating in the segregation and collection of recyclable waste in developing countries.

\section{THEORETICAL FOUNDATION AND MODEL DEVELOPMENT}

The conceptual model of the present study is a combination of the Expectation-confirmation model (ECM) and DeLone and McLean's IS success model. According to the ECM, users perceived usefulness and consequently their satisfaction and continuous use intention of service are determined by two main factors: initial expectation on a service and confirmation of expectation following the actual use of the service (Bhattacherjee, 2001). For this reason, ECM is one of the most widely used models in explaining the factors affecting continuous use intention in various fields, including in the field of mobile applications adoption (e.g., Aslam et al., 2019; Chiu et al., 2020; Humbani, Wiese, 2019; Sarkar, Khare, 2018; Tam et al., 2018; Yuan et al., 2014).

D\&M's IS success model is another widely used model in this field (e.g., Aditya et al., 2020; Ghobakhloo, Fathi, 2019; Li, 2013; Wang et al., 2019), which considers the qualities of service, system, and information as effective in discussing people's satisfaction with a service (DeLone, McLean, 1992). The combination of ECM and D\&M's IS success model has also been used in some previous studies (e.g., Li, Yin, 2017; Li et al., 2018; Liu et al., 2020; Pang et al., 2020; Veeramootoo et al., 2018; Ye et al., 2019; Zhao et al., 2015). In the present study, due to the nature of the case study, which are solid waste collection platforms and have no information aspect, such as Ye et al. (2019), only two elements of service and system qualities have been extracted from D\&M's IS success model to be considered as factors affecting people's satisfaction. Finally, the present research model is depicted in Figure 2.

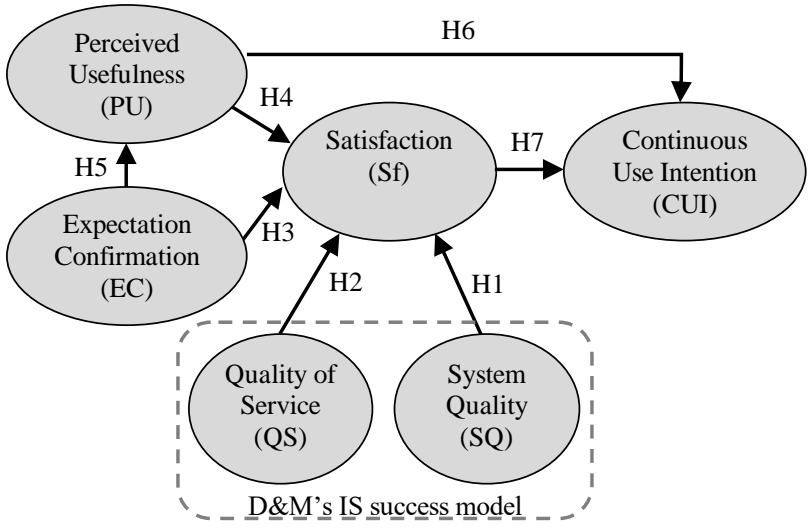

Figure 2. Research model.
Therefore, the following hypotheses are proposed based on the research model (Figure 2):

H1: System quality can positively influence user's satisfaction with the RSWC mobile app.

$\mathrm{H} 2$ : Quality of the service can positively influence user's satisfaction with the RSWC mobile app.

H3: Expectation confirmation level can positively influence user's satisfaction with the RSWC mobile app.

H4: Perceived usefulness can positively influence user's satisfaction with the RSWC mobile app.

H5: Expectation confirmation can positively influence users' perceived usefulness of the RSWC mobile app.

H6: Perceived usefulness can positively influence user's continued use intention of the RSWC mobile app.

H7: User satisfaction can positively influence user's continued use intention of the RSWC mobile app.

\section{METHODOLOGY}

\subsection{Research instrument}

A questionnaire consisting of 21 main items was designed based on the existing literature (Table 2) .Its items, like some previous studies (e.g., Aslam et al., 2019; Chiu et al., 2020; Liu et al., 2020; Pang et al., 2020; Ye et al., 2019), were built based on a five-point Likert scale from strongly disagree (1) to strongly agree (5). At the beginning of the questionnaire, citizens were asked to participate in the survey only if they had used at least one RSWC mobile app once by then. Besides, four individual questions were asked, including gender, age, work status, and RSWC mobile app usage duration.

\subsection{Sample design and data collection}

The designed questionnaire was tested by a pilot sample of 23 and prepared for online distribution by making minor changes in some questions. The public link of the final questionnaire registered in Google Forms was provided to the citizens through online social network groups and channels related to Tehran (in WhatsApp and Telegram). The response period was one week during January 2021, at the end of which 373 people completed the questionnaire. After removing the incomplete questionnaires, 302 questionnaires remained for further review. Table 1 provides the resulting distribution of survey respondents' gender, age, education, work status, and duration of RSWC mobile app usage

\begin{tabular}{|l|l|c|c|}
\hline Demographic characteristic & $\mathrm{N}$ & $\%$ \\
\hline Gender & Male & 129 & 42.7 \\
& Female & 173 & 57.3 \\
\hline Age & $<25$ & 48 & 15.9 \\
& $25-34$ & 86 & 28.5 \\
& $35-44$ & 99 & 32.8 \\
& $\geq 45$ & 69 & 22.8 \\
\hline Work status & Without job & 21 & 6.9 \\
& Housekeeper & 73 & 24.2 \\
& Retired & 35 & 11.6 \\
& Student & 67 & 22.2 \\
& Working & 106 & 35.1 \\
\hline Duration of & $\leq 3$ months & 65 & 21.5 \\
using RSWC & 3-6 months & 108 & 35.8 \\
mobile apps & 6-12 months & 86 & 28.5 \\
& $>1$ year & 43 & 14.2 \\
\hline
\end{tabular}

Table 1. Respondents' profile. 
Westland's (2012) statistical algorithm software was used to compute the minimum required sample size to ensure the adequacy of the sample size for structural equation modeling. Based on six latent variables and 21 indicator variables with a statistical power of 0.80 and a significance level of 0.05 , the lower bound on sample size for our SEM model is 138 cases. Thus, our sample of 302 meets the minimum sample size recommended for sampling adequacy (Westland, 2010).

\subsection{Data analysis}

Given that for all self-reported data, there is a possibility of bias of a common method bias (CMB) (Podsakoff et al., 2003), in this study, CMB was first evaluated using Harman's single factor test. By running a principal component factor analysis without rotation, 4-factor solutions explaining $75.018 \%$ of the variance were obtained, which the first factor was explaining only $27.591 \%$ of the variance. This indicates that method bias is not a serious issue for the present study (Podsakoff et al., 2003). The inter-correlation analysis shown in Table 3 also confirms this, as it showed no value of 0.9 or more, with the highest inter-correlation at only 0.789 .

Next, descriptive statistics of the main items and the respondents' profiles were estimated using IBM SPSS ver.26. Then, we used a partial least squares (PLS) analysis based SEM with SmartPLS ver.3.2.8 to analyze the research model. This technique has been used in some previous studies too (e.g., Deng et al., 2010; Susanto et al., 2017; Winkler et al., 2012) due to its ability to model latent constructs in nonnormal or small to medium sample sizes (Hair et al., 2013).

\section{MODEL ANALYSIS AND DISCUSSION}

\subsection{Measurement model}

At the first step, indicator reliability was evaluated by examining indicator loadings. As shown in Table 2, all item loadings exceeded the recommended value of 0.7 (Chin, 1998). Next, examination of the convergent validity criteria of the model, as shown in Table 3, indicates that the model items sufficiently reflect the properties of their respective constructs (Chin 1998) because all three criteria, containing Cronbach's alpha (Alpha), composite reliability (CR), and average variance extracted (AVE) are above the recommended thresholds (Alpha>0.7, $\mathrm{CR}>0.6, \mathrm{AVE}>0.5$, and $\mathrm{CR}>\mathrm{AVE}$ ) (Hair et al., 2013). Then, we assessed the discriminant validity with the Fornell- Larcker criterion. As depicted in table 3, the square root of the AVE of each construct (diagonal elements) is has exceeded its corresponding correlation coefficients (the offdiagonal elements). Thus this is fulfilled too (Fornell, Larcker, 1981). Overall, the psychometric adequacy of the measurement model is fully supported by convergent and discriminant validity assessments.

\begin{tabular}{|c|c|c|c|c|c|}
\hline Abbr & Item & $\mathrm{M}$ & SD & Load & Ref. \\
\hline CUI1 & $\begin{array}{l}\text { I intend to continue using the } \\
\text { RSWC mobile app rather than } \\
\text { discontinue it }\end{array}$ & 3.43 & 1.393 & 0.873 & \\
\hline CUI2 & $\begin{array}{l}\text { My intentions are to continue } \\
\text { using the RSWC mobile app } \\
\text { than use any alternative means } \\
\text { (traditional waste collection } \\
\text { services) }\end{array}$ & 3.16 & 1.244 & 0.849 & 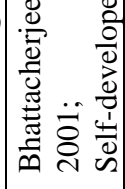 \\
\hline
\end{tabular}

\begin{tabular}{|c|c|c|c|c|c|}
\hline Abbr & Item & $\mathrm{M}$ & SD & Load & Ref. \\
\hline CUI3 & $\begin{array}{l}\text { I think from now on; I will use } \\
\text { the RSWC mobile app regularly } \\
\text { to deliver my solid waste }\end{array}$ & 3.13 & 1.370 & 0.861 & \\
\hline EC1 & $\begin{array}{l}\text { My experience with using the } \\
\text { RSWC mobile app was better } \\
\text { than what I expected }\end{array}$ & 3.19 & 1.322 & 20.835 & \\
\hline EC2 & $\begin{array}{l}\text { The service level provided by } \\
\text { the RSWC mobile app was } \\
\text { better than what I expected }\end{array}$ & 2.90 & 1.298 & 80.871 & 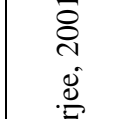 \\
\hline EC3 & $\begin{array}{l}\text { Overall, most of my } \\
\text { expectations from using the } \\
\text { RSWC mobile app were } \\
\text { confirmed }\end{array}$ & 3.05 & 1.301 & 0.841 & 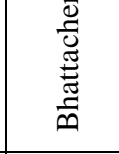 \\
\hline PU1 & $\begin{array}{l}\text { Using the RSWC mobile app } \\
\text { can lead to a more regular } \\
\text { waste collection system in my } \\
\text { city }\end{array}$ & 3.34 & 1.337 & 70.853 & \\
\hline PU2 & I find this app useful to my city & 3.42 & 1.317 & 70.814 & \\
\hline PU3 & $\begin{array}{l}\text { Using this app helps me } \\
\text { organize my waste better }\end{array}$ & 3.32 & 1.373 & 30.85 & $\cdot \frac{0}{0} \frac{0}{0}$ \\
\hline PU4 & $\begin{array}{l}\text { The service provided by the } \\
\text { RSWC mobile app is, on the } \\
\text { whole useful to me. }\end{array}$ & 3.28 & 1.380 & 0.846 & 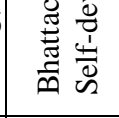 \\
\hline QS1 & $\begin{array}{l}\text { The service provided by the } \\
\text { RSWC mobile app quickly } \\
\text { processes the registered } \\
\text { requests }\end{array}$ & 2.99 & 1.238 & 80.936 & 苋 \\
\hline QS2 & $\begin{array}{l}\text { The RSWC mobile app service } \\
\text { has a reward system for waste } \\
\text { delivery, which I consider } \\
\text { appropriate. }\end{array}$ & 2.73 & 1.214 & 40.897 & 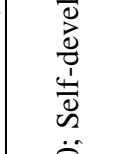 \\
\hline QS3 & $\begin{array}{l}\text { The RSWC mobile app } \\
\text { provides reliable service for its } \\
\text { users }\end{array}$ & 2.86 & 1.285 & 0.832 & ָั่ \\
\hline QS4 & $\begin{array}{l}\text { The RSWC mobile app } \\
\text { provides excellent service } \\
\text { quality on the whole }\end{array}$ & 3.13 & 1.225 & 0.864 & $\begin{array}{l}0 \\
0 \\
\tilde{\Xi} \\
\tilde{\Xi}\end{array}$ \\
\hline SQ1 & $\begin{array}{l}\text { The RSWC mobile app } \\
\text { provides helpful instructions for } \\
\text { filing my request }\end{array}$ & 2.95 & 1.311 & 0.837 & $\begin{array}{l}\dot{\pi} \\
\overrightarrow{0}\end{array}$ \\
\hline SQ2 & $\begin{array}{l}\text { The support system of the } \\
\text { RSWC mobile app quickly } \\
\text { responds to my operating } \\
\text { requirements }\end{array}$ & 2.74 & 1.295 & 0.818 & $\begin{array}{l}\ddot{\nu} \\
\ddot{\infty} \\
\ddot{2}\end{array}$ \\
\hline SQ3 & $\begin{array}{l}\text { I think the design and } \\
\text { appearance of the RSWC } \\
\text { mobile app (segmentation, } \\
\text { information classification, } \\
\text { navigation, design of function } \\
\text { buttons, etc.) is reasonable }\end{array}$ & 3.19 & 1.268 & 80.827 & 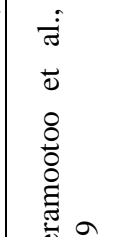 \\
\hline SQ4 & $\begin{array}{l}\text { Overall, I find the RSWC } \\
\text { mobile app system user-friendly }\end{array}$ & 3.18 & 1.268 & 80.895 & $\stackrel{\bar{d}}{>}$ \\
\hline Sf1 & $\begin{array}{l}\text { I am pleased with my } \\
\text { experience using the RSWC } \\
\text { mobile app }\end{array}$ & 2.96 & 1.214 & 40.819 & 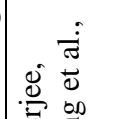 \\
\hline Sf2 & $\begin{array}{l}\text { It is a wise choice made by me } \\
\text { to use the RSWC mobile app }\end{array}$ & 2.90 & 1.310 & 0.909 & 馬 \\
\hline Sf3 & $\begin{array}{l}\text { Overall, I am satisfied with } \\
\text { using the RSWC mobile app }\end{array}$ & 3.07 & 1.261 & 10.839 & m \\
\hline
\end{tabular}

Table 2. Descriptive statistics and factor loadings of measurements 


\subsection{Structural model assessment and discussion}

As Hair et al. (2013) have suggested, for the structural model assessment, which its results are presented in Figure 3, the statistical significance of the parameter estimates (beta and tvalues) should be assessed by bootstrapping procedure with a resample of 5000. For hypothesis testing, we interpreted the path coefficients $(c)$ and explained variances $\left(\mathrm{R}^{2}\right)$ similar to parameters in a simple regression (Winkler et al., 2012).

\begin{tabular}{|c|c|c|c|c|c|c|c|c|c|}
\hline \multirow[t]{2}{*}{ 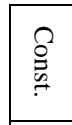 } & \multicolumn{3}{|c|}{$\begin{array}{l}\text { Convergent } \\
\text { validity criteria }\end{array}$} & \multicolumn{6}{|c|}{$\begin{array}{l}\text { Discriminant validity } \quad \begin{array}{c}\text { criteria } \\
\text { (construct correlations and } \sqrt{ } \mathrm{AVE})\end{array} \\
\end{array}$} \\
\hline & Alpha & CR & AVE & CUI & EC & PU & QS & \begin{tabular}{|l|} 
SQ \\
\end{tabular} & Sf \\
\hline CUI & 0.858 & 0.895 & 0.741 & 0.861 & & & & & \\
\hline$E C$ & 0.845 & 0.88 & 0.721 & 0.664 & 0.849 & & & & \\
\hline PU & 0.857 & 0.84 & 0.707 & 0.65 & 0.441 & 0.840 & & & \\
\hline QS & 0.805 & & & 661 & 0.602 & 0.584 & 0.883 & & \\
\hline SQ & 0.839 & 0.843 & 0.714 & 0.603 & 0.56 & 0.511 & 0.785 & 0.84 & \\
\hline $\mathrm{Sf}$ & 0.812 & 0.892 & 0.734 & 0.609 & 0.502 & 0.614 & 0.66 & 0.59 & 0.856 \\
\hline
\end{tabular}

Table 3. Convergent and discriminant validity criteria

Hypothesis 1, proposing a relationship between system quality and satisfaction, was not supported due to its $p$-value exceeding $0.05(\beta=0.125, p=0.116)$. This finding is in contradiction with most of the previous studies (e.g., Pang et al., 2020; Veeramootoo et al., 2018; Wang, Liao, 2008; Wang et al., 2019; Ye et al., 2019) that found a strong positive relationship between the two constructs and is line with the finding of some others (e.g., Aditya et al., 2020; Li, 2013). This result may be attributed to the fact that these applications do not have a unique system design. They have only a few and indifferent function buttons and some specific and similar screens designed to perform their default functions, rather than seeking the quality desired by the user.

Quality of service was found to influence user satisfaction $(\beta=0.312, p=0.000)$, supporting Hypothesis 2. This result corroborates with existing literature (e.g., Aditya et al., 2020; Veeramootoo et al., 2018; Ye et al., 2019). It is noteworthy that other researchers' findings also show that consumer satisfaction is more affected by service quality than system quality (e.g., Pang et al., 2020; Veeramootoo et al., 2018; Ye et al., 2019). In general, according to perceived time and space needed for recycling (Ittiravivongs, 2011), the services provided by RSWC mobile apps, while being timely and high quality, should also be attractive in terms of rewards (type and amount) to encourage citizens to participate more in the household waste segregation.

The result also provided support for Hypothesis 3 that proposed a positive relationship between expectation confirmation and user satisfaction $(\beta=0.102, p<0.1)$. The IS literature also reveals similar findings (e.g., Bhattacherjee, 2001; Liu et al., 2020; Pang et al., 2020; Veeramootoo et al., 2018; Ye et al., 2019; Zhao et al., 2015). This construct (EC) was found to significantly and strongly influence user's perceived usefulness too $(\beta=0.441, \quad p=0.000)$, supporting Hypothesis 5. Confirmation expectation, as a cognitive belief, referring to the extent to which users' prior expectations were actually met after the initial use of a service (Bhattacherjee, 2001), has been found to affect people's satisfaction in using various mobile-based services, such as shopping apps (Sarkar, Khare, 2018), social media apps (Aslam et al., 2019), library apps (Zhao et al., 2015), fitness and health apps (Chiu et al.,
2020; Li, Yin, 2017), travel apps (Liu et al., 2020), banking apps (Ghobakhloo, Fathi, 2019; Yuan et al., 2014), payment apps (Humbani, Wiese, 2019), and mobile apps in general (Tam et al., 2018; Ye et al., 2019). In the case of RSWC mobile apps, users' initial expectations include benefits such as ease of service request, service quality, service speed, and reward compatibility. If these initial expectations are met, perceived usefulness and user satisfaction with RSWC mobile apps and their involvement in household waste segregation will increase.

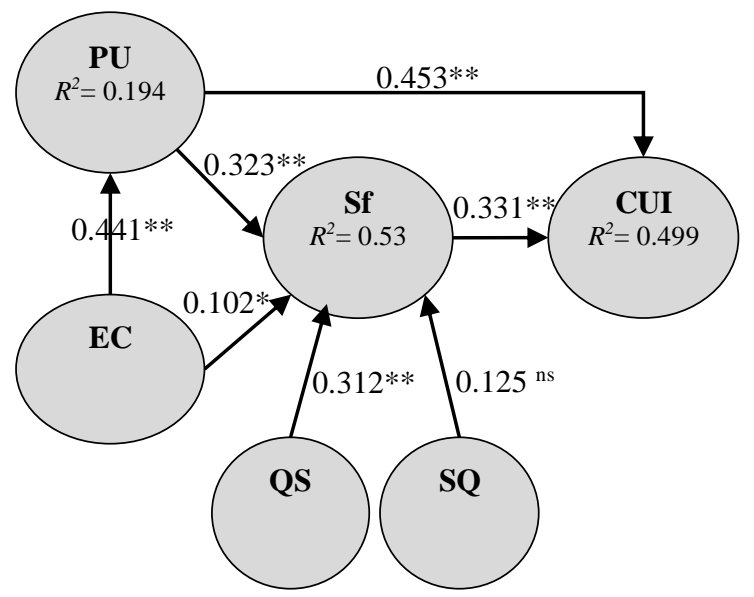

${ }^{*} \mathrm{p}<0.10 ; * * \mathrm{p}<0.01 ; \mathrm{ns}=$ not significant; $\mathrm{n}=302$

Figure 3. Structural model results

\begin{tabular}{|c|c|c|c|c|}
\hline \multicolumn{2}{|c|}{ Hypotheses } & T value & P value & Decision \\
\hline H1 & SQ $\rightarrow$ Sf & 1.571 & 0.116 & Not sup. \\
H2 & QS $\rightarrow$ Sf & 3.546 & 0.000 & Supported \\
H3 & EC $\rightarrow$ Sf & 1.749 & 0.080 & Supported \\
H4 & PU $\rightarrow$ Sf & 5.241 & 0.000 & Supported \\
H5 & EC $\rightarrow$ PU & 8.054 & 0.000 & Supported \\
H6 & PU $\rightarrow$ CUI & 5.961 & 0.000 & Supported \\
H7 & Sf $\rightarrow$ CUI & 4.553 & 0.000 & Supported \\
\hline
\end{tabular}

Table 4. Hypothesis tests

The relationship between perceived usefulness and user satisfaction was investigated by Hypothesis 4 and was found to be statistically significant $(\beta=0.323, p=0.000)$. Perceived usefulness was also found to influence user intention to continuous use intention $(\beta=0.453, \quad p=0.000)$, providing support for Hypothesis 6 . These results are both in line with most of the existing literature. Besides, it is interesting that in some other studies, in line with our findings, the intensity of the effect of perceived usefulness on people's continuous use intention is greater than its influence on their satisfaction (e.g., Aslam et al., 2019; Bhattacherjee, 2001; Pang et al., 2020; Yuan et al., 2014; Ye et al., 2019; Zhao et al., 2015). Perceived usefulness has also been recognized as an influential factor in people adopting e-government (Abu-Shanab, Haidar, 2015; Colesca. Dobrica, 2008; Mensah et al., 2017) and mgovernment (Almarashdeh, Alsmadi, 2017; Ishengoma et al., 2018; Winkler et al., 2012).

Among the various constructs of ECT, the relationship between individuals' satisfaction and their continuous usage intention has had the most validity in previous studies (e.g., Aslam et al., 2019; Bhattacherjee, 2001; Chiu et al., 2020; Humbani, Wiese, 2019; Li, Yin, 2017; Li et al., 2018; Liu et al., 2020; 
Pang et al., 2020; Sarkar, Khare, 2018; Tam et al., 2018; Veeramootoo et al., 2018; Ye et al., 2019; Yuan et al., 2014; Zhao et al., 2015). In line with these studies, our findings also support Hypothesis 7 and found a strong significant relationship between user satisfaction and continuous use intention $(\beta=0.331, p=0.000)$. Also, perceived usefulness and user satisfaction jointly explain R2 $=0.499$ of the variance in the user's intention to continue using an RSWC mobile app. This is considered as a largely consistent level of determination which is also entirely in the range of previous studies using ECM with D\&M's IS success model (e.g., Bhattacherjee, 2001; Li, 2013; Liu et al., 2020; Ye et al., 2019).

\section{CONCLUSION}

This study aimed to acquire insights into the performance of the new rewarding solid-waste collection created in Iran by understanding what factors affect the intention of citizens to continue using applications designed for this purpose. As mentioned earlier, waste recycling and management are still in their early stages in Iran; therefore, attracting people's cooperation at this stage is one of the crucial concerns of management. Our findings demonstrated that citizens' perceived usefulness and satisfaction with these apps affect their continuous use intention. Expectation confirmation and quality of the service were also found to be effective on citizens' satisfaction. While for the system quality, no significant effect was obtained in this regard.

The study outcomes suggest some directions for improving the performance of the RSWC system and mobile apps. First, based on the findings of previous studies on the impact of environmental awareness (Winkler et al., 2012) and recycling information (Ittiravivongs, 2011) on citizens' cooperation in urban and environmental affairs, it seems that the issue of educating citizens and increasing their awareness of the benefits of recycling and how to separate household waste should be considered. This educational content can be considered a separate section within the same applications to simultaneously increase the functionality and service quality of the RSWC apps. Besides, due to the proven impact of social impact on the acceptance of technology-based services (AbuShanab, Haidar, 2015; Almarashdeh, Alsmadi, 2017), it is suggested that along with citizenship education, increase the level of advertising and media and physical information about these apps and how they work in The city level should also be on the agenda of urban management and active private companies in this field.

Although the results of our research showed that the quality of system does not have a significant effect on citizen satisfaction, as mentioned earlier, in many previous studies, this relationship has been found as significant. This means that improving the quality of e-services or m-services in terms of appearance and performance can lead to increased user satisfaction and use of the system (Colesca, Dobrica, 2008; Mensah et al., 2017). Therefore, it is strongly recommended to consider as much diversity as possible in the design of these apps as well as the features available in them. Besides, to improve the quality of service, these apps are also recommended in the first place to increase their service speed. Secondly, it seems that by prioritizing the comfort of citizens in terms of time and space required for their solid waste, other
Internet-based ideas that do not require inaccessible technologies, such as smart bins, can be used.

Finally, it is hoped that the findings of this study will help urban management gain a greater understanding of what drives the adoption and development of ICT-based waste services in Iran.

\section{RECOMMENDATIONS AND SUGGESTIONS FOR FUTURE RESEARCH}

In conducting this study, one of the main limitations was the recent emergence of RSWC mobile applications in the case study, as a result of which many citizens were not yet aware of the existence of these apps. We recommend that studies in this field be done in several stages of time so that firstly, without the limitations of the present study, future studies can be done with larger sample size. Second, the performance of this system can be measured over time. Because the results of such a study can be significantly useful for urban managers, developers, and policymakers. It is also suggested that the performance of these applications in other metropolises of Iran be studied to obtain more comparable and comprehensive results. Since this research is limited to a few factors, we believe that measuring the impact of other factors such as trust and perceived risk and using other theoretical models of acceptance and use of technology will also bring valid results for future research.

\section{REFERENCES}

Ablaza-Cruz, M.M., 2019. Designing a mobile application framework as an innovative it solution for waste recycling. International Conference on Information Technology and Digital Applications, 803012046.

Abu-Shanab, E., Haider, S., 2015. Major factors influencing the adoption of m-government in Jordan. Electronic Government, 11(4), 223-240.

Aditya, H., Nurmalasari, N., Hendri, H., 2020. Success analysis of Kitabisa mobile application information system by using Delone and Mclean models. Jurnal Pilar Nusa Mandiri, 16(1), 81-88.

Almarashdeh, I., Alsmadi, M.K., 2017. How to make them use it? Citizens acceptance of m-government. Applied Computing and Informatics, 13, 194-199.

Aslam, W., Ham, M., Farhat, K., 2019. Building brand loyalty: An application of expectation confirmation model in mobile social commerce. PJCSS, 13(4), 806-825.

Behnamifard, F., Behzadfar, M., Alalhesabi, M., 2020. The impact of the rise of the information and communication age on the historical evolution of the role and leisure performance of urban spaces. 1st International and 5th National Conference on Sustainable Architecture and City, Shahid Rajaee Teacher Training University, Tehran, Iran. [Full-text in Persian]

Bhattacherjee, A., 2001. Understanding information systems continuance: An Expectation-confirmation model. MIS Quarterly, 25(3), 351-370. 
Böhm, S., Igler, B., Morales, R., Sand. F., Ertan, A., .2015. Sauberes Wiesbaden app: Introducing Mobile e-participation for a clean city project in Germany. The 14th International Conference on Mobile and Ubiquitous Multimedia, 426-429.

Chin, W.W., 1998. The partial least squares approach to structural equation modeling. In G.A. Marcoulides (Ed.), Modern methods for business research (pp.295-336). Lawrence Erlbaum Assoc.

Chiu, W., Cho, H., Chi, C.G., 2020. Consumers' continuance intention to use fitness and health apps: an integration of the expectation-confirmation model and investment model. Information Technology \& People, DOI: 10.1108/ITP-09-20190463.

Coelho, T.R., Hino, M.R.M.C., Vahldick, S.M.O., 2019. The use of ICT in the informal recycling sector: The Brazilian case of Relix. E J Info Sys Dev Countries, e12078.

Colesca, S.E., Dobrica, L., 2008. Adoption and use of egovernment services: the case of Romania. Journal of Applied Research and Technology, 6(3), 204-217.

DeLone, W.H., McLean, E.R. 1992. Information systems success: The quest for the dependent variable. Information Systems Research, 3(1), 60-95.

Deng, L., Turner, D.E., Gehling, R., Prince, B., 2010. User experience, satisfaction, and continual usage intention of IT. European Journal of Information Systems, 19, 60-75.

Fornell, C., Larcker, D.F., 1981. Evaluating structural equation models with unobservable variables and measurement error. Journal of marketing research, 18(1), 39-50.

Ghobakhloo, M., Fathi, M., 2019. Modeling the success of application-based mobile banking. Economies, 7, 114.

Hair, J.F., Hult, G.T.M., Ringle, C., Sarstedt, M., 2013: A primer on partial least squares structural equation modelling (PLS-SEM). Sage Publications, Los Angeles.

Humbani, M., Wiese, M., 2019. An integrated framework for the adoption and continuance intention to use mobile payment apps. International Journal of Bank Marketing, DOI: 10.1108/IJBM-03-2018-0072.

Ishengoma, F., Mselle, L., Mongi, H., 2018. Critical success factors for m-government adoption in Tanzania: A conceptual framework. E J Info Sys Dev Countries, e12064.

Ittiravivongs, A., 2011. Factors influence household solid waste recycling behaviour in Thailand: an integrated perspective. WIT Transactions on Ecology and The Environment, 167, 437-448.

Laartz, J., Lulf, S., 2014. Partnering to build smart cities. Government Designed for New Times, 2, 44-51.

Li, Q., Li, X., Yin, M., 2018. Continuance usage intention research of mobile group-buying-Compare and integration between ECM and IS success model. J. Mod. Inf., 38, 53-61.
Li, Q., Yin, M., 2017. Mobile app users continued subscription intention-A ECT and IS case study of health app. J. Dalian Univ. Technol. Soc. Sci., 1, 81-87.

Li, T., 2013. Applying the is success model to mobile banking apps. Master's Thesis, University of Lethbridge.

Liu, Y., Li, Q., Edu, T., Negricea, I.C., 2020. Exploring the Continuance Usage Intention of Travel Applications in the Case of Chinese Tourists. Journal of Hospitality \& Tourism Research. DOI: 10.1177/1096348020962553.

Medina, M., 2008. The informal recycling sector in developing countries Organizing waste pickers to enhance their impact. Grid Lines, Note No. 44.

Mensah, I.K., Jianing, M., Durrani. D.K., 2017. Factors influencing citizens' intention to use e-government services: A case study of South Korean students in China. International Journal of Electronic Government Research, 13(1), 14-32.

Mwikali. L.M., 2020. Bintriks: Digitizing household waste collection. B.Sc. Applied Project, ASHESI University.

Pang. S., Bao, P., Hao, W., Kim, J., Gu, W., 2020. Knowledge sharing platforms: An Empirical study of the factors affecting continued use intention. Sustainability, 12, 2341.

Podsakoff, P.M., MacKenzie, S.B., Podsakoff, N.P., Lee. J.Y., 2003. Common Method biases in behavioral research: A critical review of the literature and recommended remedies. Journal of Applied Psychology, 88(5), 879-903.

Praharaj, S., Han, J.H., Hawken, S., 2017. Innovative civic engagement and digital urban infrastructure: Lessons from 100 Smart Cities Mission in India. Procedia Engineering, 180, 1423-1432.

Sarkar, S., Arpita Khare, A., 2020. Influence of expectation confirmation, network externalities, and flow on use of mobile shopping apps. International Journal of Human-Computer Interaction, DOI: 10.1080/10447318.2018.1540383.

Šiuryte, A., 2015. An analysis of key factors in developing a smart city. Master's Thesis, Mykolas Romeris University.

Stratigea, A., Papadopoulou, C., Panagiotopoulou, P., 2015. Tools and technologies for planning the development of smart cities. Journal of Urban Technology, DOI: 10.1080/10630732.2015.1018725.

Susanto, T.D., Diani, M.M., Hafidz, I., 2017. User acceptance of e-government citizen report system (A case study of City113 app). Procedia Computer Science, 124, 560-568.

Tam, C., Santos, D., Oliveira, T., 2018. Exploring the influential factors of continuance intention to use mobile Apps: Extending the expectation confirmation model. Information Systems Frontiers, DOI: 10.1007/s10796-018-9864-5.

Veeramootoo, N., Nunkoo, R., Dwivedi, Y.K., 2018. What determines success of an e-government service? Validation of an integrative model of e-filing continuance usage. Government Information Quarterly, DOI: 10.1016/j.giq.2018.03.004. 
Walravens, N., 2014. Mobile city applications for Brussels citizens: Smart City trends, 4 challenges and a reality check. Telematics and Informatics. DOI: 10.1016/j.tele.2014.09.004

Wang, Y.S., Liao, Y.W. 2008. Assessing e-government systems success: A validation of the DeLone and McLean model of information systems success. Government Information Quarterly, 25, 717-733.

Wang, Y.Y., Wang, Y.S., Lin, H.H., Tsai, T.H., 2019. Developing and validating a model for assessing paid mobile learning app success. Interactive Learning Environments, 27(4), 458-477.

Westland, J.C., 2010. Lower bounds on sample size in structural equation modeling. Electronic Commerce Research and Applications, 9, 476-487.

Westland, J.C., 2012. Erratum to "Lower bounds on sample size in structural equation modeling'. Electronic Commerce Research and Applications, 11, 445.

Wilson, A., Tewdwr-Jones, M., Comber, R., 2019. Urban planning, public participation and digital technology: App development as a method of generating citizen involvement in local planning processes. Environment and Planning B: Urban Analytics and City Science, 46(2), 286-302.

Winkler, T.J., Hirsch, H., Trouvilliez, G., Günther, O., 2012. Participatory urban sensing: Citizens' acceptance of a mobile reporting service. ECIS 2012 Proceedings. 106.

Ye, Q., Luo, Y., Chen, G., Guo, X., Wei, Q., Tan, S., 2019. Users intention for continuous usage of mobile news apps: The roles of quality, switching costs, and personalization. Journal of Systems Science and Systems Engineering, 28(1), 91-109.

Yeh, H., 2017. The effects of successful ICT-based smart city services: From citizens' perspectives. Government Information Quarterly, DOI: 10.1016/j.giq.2017.05.001.

Yuan, S., Liu, Y., Yao, R., Liu, J., 2014. An investigation of users' continuance intention towards mobile banking in China. Information Development, 1-15.

Zhao, Y., Deng, S., Zhou., R., 2015. Understanding mobile library apps continuance usage in China: A theoretical framework and empirical study. LIBRI, 65(3), 161-173. 